\title{
1 The life of the Bronze Age
}

This book concerns a period of the past that was dynamic and world-changing, the Bronze Age in Europe. Of course most scholars can make a case that the period they study was just as dynamic, and changed the world just as much as the Bronze Age did, but I shall argue in these pages that what happened in Europe between 2500 and $800 \mathrm{BC}$ was so remarkable that it transcends the achievements of any period that went before it, and foreshadowed the technical and social developments of the Iron Age, themselves a direct prelude to the achievements of the Graeco-Roman world.

The Bronze Age was a period that spanned some 1700 years, from around $2500 \mathrm{BC}$ to around $800 \mathrm{BC}$ - depending on area and definition (e.g. whether the Beaker period is regarded as belonging to the Copper Age or the Bronze Age). Traditionally it has been divided into three main chunks, usually labelled Early, Middle and Late, roughly 2500-1800, 1800-1300, and 1300-800 BC (scholars in individual countries have their own way of describing and dividing the material). In this book I use these labels in a general way, without making any assumptions about exact chronology - though in Chapter 5 I do consider the radiocarbon dates from two sites, with a view to establishing episodes of violence. Radiocarbon dating is now so developed, particularly when large series of dates can be subjected to Bayesian analysis, that it is already possible in some areas to indicate a refined chronology for the period, or at least some parts of it. In areas where there are still not enough dates for this purpose (either because not enough suitable samples have been encountered, or because of local prejudices against the method), the way to get a reliable chronology is now quite clear. Dates given in this book are based on radiocarbon, and should therefore be followed by "cal BC" rather than BC. In reality, however, this account is not about chronology or typology, and anyone seeking to study such matters should look elsewhere.

\section{The Bronze Age as an object of study}

Study of the Bronze Age goes far back into the history of archaeology. Our academic ancestors, Oscar Montelius (1843-1921), Joseph Déchelette (1862-1914), Paul Reinecke (1872-1958), V. Gordon Childe (1892-1957), Ernst Sprockhoff (1892-1967), and many others, laid the foundations for our knowledge of the period. They all predate any of today's scholars active in the field, in most cases by many years. The immediate forefathers of my generation, scholars such as Chris- 
topher Hawkes (1905-1992), Stuart Piggott (1910 - 1996), Jean Deshayes (19241979), Hermann Müller-Karpe (1925-2013), or Bernhard Hänsel (1937-2017), all of whom I knew, built on the foundations of that earlier generation (some of whom they themselves met), and in turn influenced the generation to which I myself belong. Today's leaders in the study of the Bronze Age, people such as Albrecht Jockenhövel (b. 1943), Kristian Kristiansen (b. 1948), or Richard Bradley (b. 1946, the same year and month as me), all grew up academically under the influence of that earlier generation, and while it is not the habit in the AngloSaxon world to write fawning acknowledgements of and tributes to our academic mentors, there is no doubt that these titans of research had a major influence on what we ourselves have written and done.

The Bronze Age, like most periods, has undergone the changes that archaeology itself has experienced. In the $19^{\text {th }}$ century and for a large part of the $20^{\text {th }}$, it was concerned above all with artefacts, and with placing those artefacts into groups that had a meaningful similarity or association, in other words typology. The fact that the period saw a huge production of metal objects, mostly copper or bronze, lent this mode of study importance and credibility. Of course there were also excavations of major sites, in every country of Europe, which revealed houses (e.g. Swiss lake sites such as Cortaillod-Est or Auvernier), fortifications (e.g. the Wittnauer Horn in canton Aargau, Switzerland, or Fort Harrouard, Eure-etLoir, France) or elaborate burial structures (e.g. the famous sites of Helmsdorf in Thuringia or Leubingen in Sachsen-Anhalt, or the barrows of the Eight Beatitudes in North Brabant, the Netherlands); especially the latter, where total excavation was possible so that complete plans could be recovered (which was not usually the case with settlements or forts). For the most part, however, it was the objects recovered from such excavations that held people's attention. Even with the sensational discovery of the Uluburun ship in 1981, it was above all and understandably the cargo that attracted most attention. It was during this period, too, that two great corpora of material started their lives: Prähistorische Bronzefunde in 1969 under the direction of Hermann Müller-Karpe, and Die Funde der älteren Bronzezeit des nordischen Kreises in Dänemark, Schleswig-Holstein und Niedersachsen in 1973 under the direction of Ekkehard Aner and Karl Kersten. There had been earlier efforts at the systematic publication of bronzes in the Inventaria Archaeologica card series (promoted by the Union International des Sciences Pré- et Protohistoriques) but while a few countries managed to produce a significant number of cards (notably Poland), in general the series produced little reaction in the Bronze Age world. The British Museum, for instance, after an initial burst of enthusiasm which saw the publication of nine card sets (1955-1968), later produced something similar in its own series British Bronze Age Metalwork (1985-1994) before abandoning this type of publication for good. 
In the 1960s and 1970s, at the birth of the "New Archaeology", attention turned to environmental aspects of the Bronze Age - both the natural environment in which people lived (above all vegetation), and the economies of Bronze Age societies (animal and plant remains). At the same time, analytical methods derived from the natural sciences enabled the development of techniques for determining the provenance of materials and artefacts, especially metals, for example the huge Stuttgart programme of metal analysis, Studien zu den Anfängen der Metallurgie (Junghans et al. 1960, 1968, 1974). In this way pottery, glassy substances such as faience, and stones such as obsidian were tied down to their sources or source areas with greater or lesser degrees of certainty.

The 1980s and 90s saw both a continuation of these techniques and a move towards new ways of interpreting the evidence; this was the period when socalled post-processual archaeology developed, its echoes being found in Bronze Age research as in that of other periods. So we see a classic piece of post-processual archaeology in Chris Tilley's Phenomenology of Landscape (1994), or the excavation of the Cornish Bronze Age settlement at Leskernick (Bender et al. 1997; Bender et al. 2007). It has to be said that this movement found little resonance in the Bronze Age research of other countries, though similar approaches were attempted in Scandinavia and the Netherlands; some of these works are referenced in the chapters that follow.

Many people saw some of the developments in what is loosely called postprocessual archaeology as undesirable, in particular the apparent relativism that it promoted - in the sense that multiple interpretations of phenomena were permissible, whether or not the interpreter was "qualified" (through academic upbringing or experience) to express an opinion. In spite of protests by promoters of this line of thought that such confusion was unlikely, many older scholars remained critical of the approach - which indeed has spawned a large industry of "alternative archaeology" (cf below).

The $21^{\text {st }}$ century has seen a remarkable set of developments in Bronze Age research, led above all by advances in genetic and isotopic work. The ability to extract DNA from ancient bones, long thought to be impossible because of the likelihood of contamination, has now become almost routine, provided suitable bones or teeth are available. This, coupled with the existence of large genetic databases of modern populations, has enabled geneticists to build up a remarkable picture of Bronze Age ancestry. At the same time, studies using stable isotopes have allowed analysts to identify not only aspects of diet (for instance marine as opposed to terrestrial food sources) but also the relationship between individuals and the environment in which they lived (geology, groundwater), leading to the ability to detect where they spent their lives, in other words whether they moved their place of residence between different environments 
over the course of their life. This has led to remarkable results in many areas where it has been applied.

At present, there seems to be less divergence between different clans of archaeologists than used to be the case. Some younger scholars in some countries continue to produce what one may call "speculative" books and articles, based on a highly restricted perusal of the literature; this tendency is particularly evident in anglophone countries, where anything written in a language other than English is relegated to the "not worth reading" or "can't read" pile, if it is even noticed at all (a tendency also apparent, though to a lesser extent, in France); by contrast, many European countries have embraced a range of approaches derived from wide reading in a number of languages, notably English. ${ }^{1}$ Evžen Neustupný proposed that part of this tendency is to be attributed to "mainstream" and "minority" communities of scholars, the former who have a big enough body of scholarship in their own language to be able to ignore the latter, the latter being forced to work with the output of the large ones (Neustupný 1997-98). In general across Europe, however, there has been a welcome move towards the idea that we are all studying the same material and have a range of different ways of doing it. To take one example: in central Europe it always used to be the case that doctoral students would study a group of material culture (artefacts), usually assigned them by their professor; they would catalogue it, order it into types, consider its analogues near and far, and produce a large tome that described all this material in great detail. While this method of study is far from dead, it is reassuring to find that other aspects have now entered the mainstream, for instance environment and ecology, the potential of artefacts to tell us more than what type they belonged to, or the implications of material culture for telling a story of the Bronze Age that sees the people behind the objects.

The Bronze Age has not, however, been immune to the deluge of misinformation and fantasy that has engulfed the world in recent times. Of course this is not new; books such as the zoologist Barry Fell's Bronze Age America (1982) were being turned out decades ago. A quick search of the internet will reveal numerous examples of pseudo-scholarly works that provide a version of the Bronze Age unhampered by knowledge or understanding of the evidence, concerned instead to peddle a story about the past that has no foundation in real-world data. In today's world, where scientists are regarded with suspicion and their opinions

1 A study by Kristian Kristiansen and his students showed that the literature in English was embarrassingly short of references to material in other languages: Lang 2000; Kristiansen 2012, 467. While this is true, the statement that Stuart Piggott was restricted in his foreign language reading compared to Gordon Childe is erroneous. 
no better than those of film stars or conspiracy theorists, regardless of qualification to pronounce on subjects, this is probably only to be expected. The relativism that has been promoted by various well-respected authorities, which regards "facts" as entirely context and viewer-dependent, has had a large part to play in this. I would of course maintain that interpretations can and must vary; there cannot be just one version of Bronze Age "history". But such interpretations must, in my view, be based on archaeological data. Archaeological "facts" consist of artefacts and ecofacts (in a broad sense). Everything else is interpretation. It is astonishing to me that so many words have been written in recent years that seem to forget this. Speculation has its place, but it must always be labelled as such. $^{2}$

\section{Coda}

The Bronze Age has thus had, and continues to have, many different lives. When one looks at those parts of the archaeological record that attract most attention in the semi-popular press, it is often the earliest periods that feature most prominently, from the emergence of hominins in Africa to the discovery of late hominin types such as Denisovans and Homo floresiensis, the survival of Neanderthals and the appearance of modern humans. For Neolithic specialists, the recent dating programmes led by Alasdair Whittle and Alex Bayliss (Gathering Time and The Times of their Lives) have been ground-breaking, though unknown to the general public (Whittle et al. 2011; Whittle 2018). In the 1990s the Bronze Age attracted much attention through the Council of Europe's promotion of the European Campaign for Archaeology, featuring the Bronze Age - the "First Golden Age of Europe", with conferences and workshops, culminating in a travelling exhibition "Gods and Heroes of the Bronze Age" in 1998-99. This was undoubtedly the most visible promotion of the Bronze Age in recent times. Since then, it is hard to think of public presentations that have had the same impact, with one exception: the Nebra sky-disc (Meller \& Bertemes 2010). The story of the discovery and recovery of this extraordinary object is well-known; it was a sensation both because of how it was acquired and because of its nature. It was the centre-

2 I refrain from discussing the case of the gold and amber objects emanating from Bernstorf, Ldkr. Freising, Bavaria, other than to point to the fantastical speculation by a classical scholar on how the supposed Linear B signs are to be interpreted (Janko 2015). No established Linear B scholar has accepted his conclusions, which were published in a journal that does not normally cover linguistic or philological matters. It would be interesting to know whether this article was submitted for independent peer review to Linear B specialists. 
piece of a magnificent exhibition in Halle in 2004-05 and still amazes visitors with its depiction of the heavenly bodies, even if its interpretation is a matter of intense debate.

Naturally Bronze Age archaeology does not have to be spectacular, but discoveries like this are of interest to more than a narrow circle of specialists. One might say the same for the site of Nola in Campania, destroyed in the Avellino eruption of Vesuvius around 1900 BC (Laforgia et al. 2009; Albore Livadie et al. 2018; Alessandri 2019); or the recent excavation of Must Farm in Cambridgeshire, eastern England, which has produced large numbers of organic artefacts that were hitherto mostly known from Alpine lake sites (Knight et al. 2019). These, and the much larger numbers of "ordinary" sites are what creates the Bronze Age in our lives and minds, and creates a "life" for the period as an entity in itself.

The period we call the Bronze Age was thus created over the last 100 years by a number of people, mostly university or museum archaeologists. The life it possesses also engenders a life in those people who work in it, of whom I am one. These intertwining lives were the rationale for the lectures given in 2015-16, and for this book. 